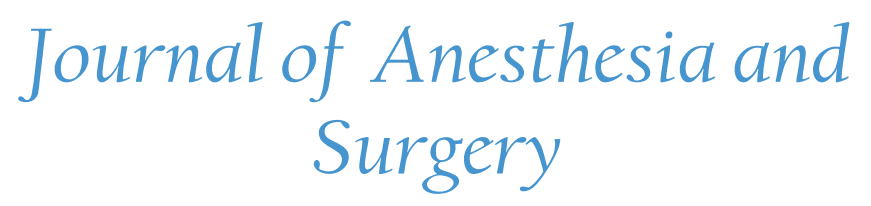

\title{
Subcostal Transversus Abdominis Plane (STAP) Block with Depot Steroids in the Management of Upper Abdominal Myofascial Pain Syndrome (AMPS)
}

\author{
G Niraj FFPMRCA*
}

Consultant, Department of Pain Medicine, Clinical Research Unit in Pain Medicine, University Hospitals of Leicester NHS Trust

*Corresponding author: Dr. Niraj, G. Consultant, Department of Anaesthesia and Pain Medicine, Honorary Senior Lecturer, University of Leicester, Clinical Research Unit in Pain Medicine, University Hospitals of Leicester, Gwendolen Road, Leicester, LE5 4PW, E-mail: nirajgopinath@yahoo.co.uk

\begin{abstract}
Background: Abdominal myofascial pain syndrome is a poorly recognised cause of chronic abdominal wall pain. Diagnosis is confirmed by a positive response to trigger point injection. In the presence of extensive myofascial pain, trigger point treatment can result in patient discomfort and distress. Recently, posterior transversus abdominis plane blocks have been reported in the diagnosis and treatment of chronic abdominal wall pain. Subcostal transversus abdominis plane block is an abdominal wall block that is effective for pain arising from the upper abdomen. The report describes the role of the ultrasound guided subcostal transversus abdominis plane block in the management of abdominal myofascial pain syndrome. Methods: Adult patients with myofascial pain syndrome localised in the upper abdomen under the care of a single physician at a tertiary pain medicine unit were offered bilateral ultrasound guided subcostal transversus abdominis plane block with a mixture of local anaesthetic and depot methylprednisolone instead of multiple trigger point injections as a part of an on-going prospective longitudinal audit into the management of abdominal myofascial pain syndrome. Patients completed brief pain inventory questionnaire at baseline and at 12 weeks post procedure.

Results: Twenty patients underwent bilateral subcostal transversus abdominis plane blocks with depot steroids. All patients reported complete absence of pain within 15 minutes of the block. Clinically significant benefit at 12 weeks was reported by $60 \%(12 / 20)$ of patients.

Conclusion: Subcostal transversus abdominis plane block with depot steroids could play a role in the management of myofascial pain of the upper abdomen.
\end{abstract} Received date: September 18, 2017 Accepted date: October 10, 2017

Published date: October 12, 2017

Citation: Niraj, G. Subcostal Transversus Abdominis Plane (STAP) Block with Depot Steroids in the Management of Upper Abdominal Myofascial Pain Syndrome (AMPS). (2017) J Anesth Surg 4(2): 111- 114.

DOI: $10.15436 / 2377-1364.17 .093$

\section{Introduction}

Abdominal myofascial pain syndrome (AMPS) is a common but often poorly recognised cause of chronic abdominal wall pain (CWAP) ${ }^{[1-3]}$. The underlying pathology is the presence of trigger points in the abdominal musculature that induce abnormal muscle relaxation and muscle function ${ }^{[3,4]}$. Trigger points in the abdomen develop as a result of either trauma or can be secondary to underlying visceral inflammation (viscerosomatic convergance)[3-7]. Common conditions that produce visceral inflammation and subsequent myofascial pain in the up- per abdomen include poorly controlled gastro-oesophageal reflux disease (GORD), gastritis, pancreatitis and cholecystitis ${ }^{[3,4]}$. Severe vomiting and retching induced by gastritis secondary to alcohol excess can result in the development of trigger points in the upper rectus muscle. In this scenario, both traumatic injury to the upper rectus muscle and underlying visceral inflammation play a role in muscle dysfunction. Port scars from laparoscopic cholecystectomy can result in persistent pain in the upper abdomen.

Clinical diagnosis is confirmed by performing diagnostic trigger point injection(s) usually under ultrasound guid- 
ance $^{[3,8]}$. Misdiagnosis can result in significant healthcare costs as a result of unnecessary investigations and diagnostic surgical interventions ${ }^{[1,3]}$. Patients often have multiple tender points in the upper rectus muscle as well as in the muscles that constitute the anterolateral abdominal wall (external and internal oblique and transversus abdominis). Multiple trigger point treatment cause significant discomfort, distress and often result in post-procedural flare up that can last for days ${ }^{[3]}$.

Recently, posterior transversus abdominis plane (PTAP) blocks have been reported in the management of CAWP ${ }^{[9,10]}$. However, PTAP provides sensory cover for the lower abdomen (dermatomes thoracic T10 - lumbar L1) ${ }^{[11,12]}$. Subcostal transversus abdominis plane block (STAP) is a well-established abdominal wall block where the local anaesthetic agent is deposited in a fascial plane between the rectus abdominis and transversus abdominis muscles (Figure 1). STAP provides sensory block for pain arising from the upper abdomen ${ }^{[13,14]}$. The author presents the first report on the use of ultrasound guided subcostal transversus abdominis plane block with depot steroid in the management of AMPS arising from the upper abdomen.

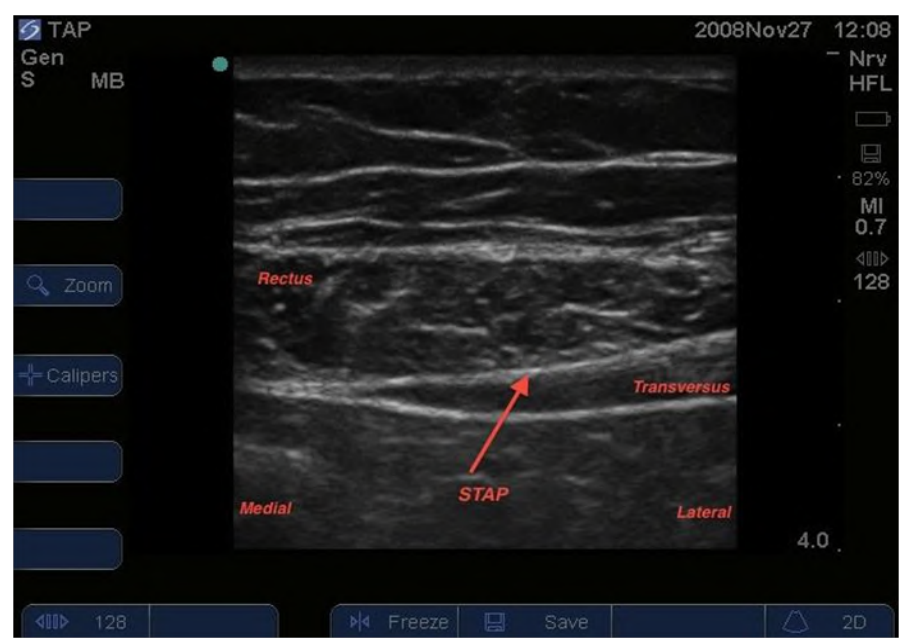

Figure 1: The subcostal transversus abdominis plane (STAP) between the rectus muscle and the transversus abdominis muscle.

\section{Methods}

Adult patients diagnosed with abdominal myofascial pain syndrome of the upper abdomen under the care of a single pain physician based in a tertiary pain medicine service were offered STAP block with a mixture of local anaesthetic and depot steroid as an alternative to multiple trigger point injections as a part of an on-going prospective audit into the management of AMPS $^{[3]}$. TAP blocks are currently used in the management of CWAP at the author's centre. The lead author has experience of performing abdominal wall blocks including STAP blocks in the perioperative setting ${ }^{[12,13]}$. Patients with multiple trigger points in the upper abdomen ( $>5$ triggers) were offered the novel block instead of multiple TPIs.

The objective was to identify if STAP with depot steroids could reduce patient discomfort, reduce incidence of post procedural flare up and provide an improved therapeutic benefit at 12 weeks following treatment. Informed consent was obtained prior to the procedure. Patients were given detailed information on the technique, potential risks and the objective for offering a novel procedure (reduced discomfort). All patients provided written consent for their de-identified data to be used for analysis and for publication in a peer reviewed journal.

Patients received bilateral ultrasound guided STAP block with a mixture of local anaesthetic and depot steroids. They received $10 \mathrm{mls}$ of $0.5 \%$ levo-bupivacaine and $40 \mathrm{mg}$ of depot steroid on each side. Following STAP, a specialist nurse in pain medicine followed up the patients over telephone at 12 weeks.

Patients completed Brief Pain Inventory Short Form (BPI-SF) and quality of life (EQ 5D) questionnaires at baseline and at 12 weeks months after treatment (returned by post). Clinically significant pain relief was defined using the 'Pain at its worst in the last 24 hours' construct in the Brief Pain Inventory Short Form (BPI-SF) questionnaire. This 11-point pain intensity Numerical Rating Scale (NRS) has been found to have the strongest relationship with the pain interference scale ${ }^{[15,16]}$. Following IMMPACT recommendations (Initiative on Methods, Measurement, and Pain Assessment in Clinical Trials), a 2-point change (30 - 36\%) at 12 weeks post treatment was considered as successful therapeutic intervention ${ }^{[17]}$. Ultrasound guided STAP was performed as previously described ${ }^{[14]}$.

\section{Results}

Over a 9-month period, 21 patients with AMPS in the upper abdomen were offered STAP with depot steroids instead of repeat multiple TPIs. All patients had over 5 trigger points. In one patient, ultrasound scanning revealed severe postsurgical scarring of the STAP fascial plane (total pancreatectomy) and the procedure was abandoned. This patient underwent trigger point injections ( 7 triggers) that resulted in significant post-procedural flare up.

Bilateral ultrasound guided subcostal transversus abdominis plane block (STAP) was performed in 20 patients. Demographic characteristics are detailed in Table 1. All patients tolerated the procedure under local anaesthetic and did not require additional sedation.

Table 1: Patient characteristics and duration of relief following Subcostal Transversus Abdominis Plane (STAP) block with depot steroids.

\begin{tabular}{|c|l|c|l|l|}
\hline $\begin{array}{l}\text { Patient } \\
\text { ID }\end{array}$ & $\begin{array}{l}\text { Gender, } \\
\text { Age } \\
\text { year) }\end{array}$ & $\begin{array}{l}\text { Duration } \\
\text { of pain } \\
\text { (year) }\end{array}$ & $\begin{array}{l}\text { Primary visceral } \\
\text { inflammation }\end{array}$ & $\begin{array}{l}\text { D u ration } \\
\text { of 30\% } \\
\text { Relief with } \\
\text { TQLB }\end{array}$ \\
\hline 1 & M, 52 & 11 & Gastritis & 6 weeks \\
\hline 2 & F, 39 & 2 & Gastritis, Biliary & 12 weeks \\
\hline 3 & M, 47 & 2 & Gastritis, Pancreatitis & 12 weeks \\
\hline 4 & M, 23 & 1 & $\begin{array}{l}\text { Post Liver Cyst } \\
\text { De-roofing }\end{array}$ & 12 weeks \\
\hline 5 & F, 45 & 1 & Hiatus Hernia & 12 weeks \\
\hline 6 & F, 38 & 2 & Gastritis & 12 weeks \\
\hline 7 & F, 38 & 3 & Gastritis, Pancreatitis & 12 weeks \\
\hline 8 & M, 34 & 17 & $\begin{array}{l}\text { Gastritis, Lap port } \\
\text { scar pain }\end{array}$ & 12 weeks \\
\hline 9 & M, 50 & 3 & Pancreatitis & 1 week \\
\hline 10 & M, 63 & 20 & Pancreatitis, Gastritis & 2 weeks \\
\hline 11 & F, 23 & 3 & Pancreatitis, Gastritis & 6 weeks \\
\hline 12 & F, 44 & 3 & Pancreatitis & 6 weeks \\
\hline 13 & F, 52 & 1 & $\begin{array}{l}\text { Hiatus Hernia, } \\
\text { Biliary }\end{array}$ & 12 weeks \\
\hline & & & \\
\hline
\end{tabular}

J Anesth Surg | volume 4 : issue 2


Subcostal Transversus Abdominis Plane

\begin{tabular}{|c|l|c|l|l|}
\hline \hline 14 & M, 56 & 4 & Pancreatitis & 12 weeks \\
\hline 15 & M, 54 & 5 & Post Traumatic & 12 weeks \\
\hline 16 & F, 65 & 8 & $\begin{array}{l}\text { Pancreatitis, Post } \\
\text { surgical }\end{array}$ & 6 weeks \\
\hline 17 & M, 57 & 2 & Gastritis & 12 weeks \\
\hline 18 & F, 28 & 3 & Pancreatitis, Gastritis & 12 weeks \\
\hline 19 & F, 33 & 1 & Biliary & 1 day \\
\hline 20 & F, 27 & 2 & Gastritis & 4 weeks \\
\hline 21 & F, 49 & 10 & $\begin{array}{l}\text { Total pancreatecto- } \\
\text { my, Gastritis }\end{array}$ & Abandoned \\
\hline
\end{tabular}

Clinically significant pain relief at three months following STAP was reported by $60 \%(12 / 20)$ (Table 2$)$. Five patients reported benefits that lasted between $4-6$ weeks. In three patients, the relief was transient. None of the patients reported post-procedural flare-up in pain. There were no complications.

Table 2: Brief pain inventory short form (BPI-SF) scores and quality of life (Euro-QoL) at baseline and at 12 weeks post Subcostal Transversus Abdominis Plane (STAP) Block with depot steroids.

\begin{tabular}{|c|c|c|c|}
\hline \multirow[t]{2}{*}{ Patient ID } & $\begin{array}{l}\text { Baseline } \\
\text { Worst Pain }\end{array}$ & $\begin{array}{l}12 \text { weeks } \\
\text { Worst Pain }\end{array}$ & 12 weeks \\
\hline & Score in $24 \mathrm{~h}$ & Score in $24 \mathrm{~h}$ & EQ-5D \\
\hline 1 & 7 & 7 & Same \\
\hline 2 & 7 & 3 & Better \\
\hline 3 & 8 & 5 & Better \\
\hline 4 & 8 & 6 & Better \\
\hline 5 & 8 & 6 & Better \\
\hline 6 & 8 & 5 & Better \\
\hline 7 & 10 & 0 & Better \\
\hline 8 & 6 & 0 & Better \\
\hline 9 & 9 & 9 & Same \\
\hline 10 & 10 & 9 & Same \\
\hline 11 & 9 & 9 & Same \\
\hline 12 & 7 & 8 & Worse \\
\hline 13 & 9 & 5 & Better \\
\hline 14 & 8 & 0 & Better \\
\hline 15 & 10 & 6 & Better \\
\hline 16 & 9 & 8 & Same \\
\hline 17 & 7 & 5 & Better \\
\hline 18 & 9 & 4 & Better \\
\hline 19 & 8 & 9 & Worse \\
\hline 20 & 7 & 7 & Same \\
\hline 21 & 9 & $\begin{array}{l}\text { Procedure } \\
\text { abandoned }\end{array}$ & \\
\hline
\end{tabular}

\section{Discussion}

The author presents the first report on the use of ultrasound guided subcostal transversus abdominis plane (STAP) block in the management of abdominal myofascial pain syndrome (AMPS) arising from the upper abdomen. AMPS is one of the two common types of chronic abdominal wall pain (CWAP), the other being anterior cutaneous nerve entrapment syndrome $(\mathrm{ACNES})^{[1-3]}$.
Trigger point treatment is crucial in both diagnosis and management of AMPS ${ }^{[2,3,8]}$. In the presence of multiple trigger points, this intervention can cause significant distress, increases risk of visceral injury especially if the procedure is performed using a landmark technique, and there is a possibility of missing trigger points in the muscle. Multi injections also increase the risk of post-procedural flare up that could negate the benefit of the treatment ${ }^{[3]}$.

Two types of TAP blocks have been described ${ }^{[1-14]}$. The subcostal TAP block covers the thoracic dermatomes from T6 to T10. The posterior TAP block provides sensory block to the lower abdomen (dermatomes T10-L1). Posterior TAP block does not reliably cover dermatomes above T10 dermatome. The presence of this watershed zone at T10 dermatome has been confirmed by both anatomical and clinical studies ${ }^{[11-14]}$. Commonly performed posterior TAP (PTAP) block has been reported in the management of chronic abdominal wall pain ${ }^{[9,10]}$. PTAP will be ineffective in patients presenting with upper abdominal CWAP.

The average duration of relief following abdominal trigger point injection is reported to range from $6-12$ weeks $^{[8,18]}$. STAP provided on-going relief at 12 weeks in $60 \%$ patients in this series. This is similar to the $43 \%$ reported by Alnahhas et al in their series following ultrasound guided trigger point injec$\operatorname{tion}^{[8]}$.

Abdominal myofascial pain syndrome is a common and often unrecognised clinical entity that can utilise significant health care costs ${ }^{[1-3]}$. This report in a limited cohort suggests ultrasound guided STAP as an alternative technique to trigger point injection in the management of upper abdominal myofascial pain syndrome. Further work is required to confirm the therapeutic benefit of STAP block with depot steroids in the management of AMPS.

Funding: Supported by University Hospitals of Leicester NHS Trust.

Acknowledgement: The author would like to sincerely thank the chronic pain specialist nursing team at Leicester General Hospital for performing the post-procedural follow-up of patients.

Conflict of interest: The author declares no conflict of interest. 


\section{References}

1. Constanza, C.D., Longstreth, G.F., Liu, A.L. Chronic abdominal wall pain: clinical features, health care costs, and long-term outcome. (2004) Clin Gastroenterol Hepatol 2(5): 395-399.

Pubmed | Crossref | Others

2. Johlin, F.C., Buhac, J. Myofascial pain syndromes: An important source of abdominal pain for refractory abdominal pain. (1996) Gastroenterology 110(4 Suppl): A808.

Pubmed | Crossref $\mid$ Others

3. Niraj, G., Chaudhri, S. Prospective Audit of a Pathway for In-Patient pain management of Chronic Abdominal Pain: a Novel and Cost Effective strategy. (2017) Pain Med (in press).

Pubmed | Crossref | Others

4. Gerwin, R.D. Myofascial and visceral pain syndromes: visceral-somatic representations. (2002) J Musculoskeletal Pain10: 165-175.

Pubmed | Crossref | Others

5. Giamberardino, M.A. Visceral hyperalgesia. Proc 9th World Congress on Pain. (2000) Progr Pain Res Man Seattle IASP Press 16: 523 550.

Pubmed $\mid$ Crossref $\mid$ Others

6. Sikandar, S., Dickenson, A.H. Visceral pain-Ins and Outs, the Ups and Downs. (2012) Curr Opinion Support Palliat Care 6(1): 17-26.

Pubmed | Crossref $\mid$ Others

7. Gebhart, G. Visceral pain-peripheral sensitisation. (2000) Gut 47 (Suppl 4): iv 54-55.

Pubmed | Crossref | Others

8. Alnahhas, M.F., Oxentenko, S., Locke, G.R., et al. Outcomes of ultrasound guided trigger point injection for abdominal wall pain. (2016) Dig Dis Sci 61(2): 572-577.

Pubmed | Crossref | Others

9. Soliman, L.M., Narouze, S. Ultrasound-guided transversus abdominis plan block for the management of abdominal pain: an alternative to differential epidural block. (2009) Tech Reg Anesth Pain Manag 13(3): 117-120.

Pubmed $\mid$ Crossref $\mid$ Others

10. Guirguis, M.N., Abd-Elsayed, A.A., Girgis, G., et al. Ultrasound-Guided Transversus Abdominis Plane Catheter for Chronic Abdominal Pain. (2013) Pain Pract 13(3): 235-238.

Pubmed | Crossref | Others
11. Tran, T.N., Rozen, W., Ashton, M., et al. Refining the course of the thoracolumbar nerves: a new understanding of the innervation of the anterior abdominal wall. (2008) Clin Anatomy 21: 325-333.

Pubmed | Crossref | Others

12. Niraj, G., Kelkar, A., Hart, E., et al. Comparison of analgesic efficacy of four- quadrant transversus abdominis plane (TAP) block and continuous posterior TAP analgesia with epidural analgesia in patients undergoing laparoscopic colorectal surgery: an open-label, randomised, non-inferiority trial. (2014) Anaesthesia 69(4): 348-355.

Pubmed | Crossref | Others

13. Hebbard, P. Subcostal transversus abdominis plane block under ultrasound guidance. (2008) Anesth Analg 106(2): 674-675.

Pubmed | Crossref | Others

14. Niraj, G., Kelkar, A., Jeyapalan, I., et al. Comparison of analgesic efficacy of subcostal transversus abdominis plane blocks with epidural analgesia following upper abdominal surgery. (2011) Anaesthesia 66(6): 465-471.

Pubmed | Crossref | Others

15. Serlin, R.C., Mendoza, T.R., Nakamura, Y., et al. When is cancer pain mild, moderate or severe? Grading pain severity by its interference with function. (1995) Pain 61: 277-284.

Pubmed | Crossref | Others

16. Atkinson, T.M., Mendozam, T.R., Sit, L., et al. The Brief Pain Inventory and its "Pain at its Worst in the last 24 Hours" Item: Clinical Trial Endpoint Considerations. (2010) Pain Med 11(3): 337-346. Pubmed | Crossref | Others

17. Dworkin, R.H., Turk, D.C., Wyrwich, K.W., et al. Interpreting the clinical importance of treatment outcomes in chronic pain clinical trials: IMMPACT recommendations. (2008) J Pain 9(2): 105-121.

Pubmed | Crossref | Others

18. Porto, M. A comparative trial of Botulinum toxin type A and methylprednisolone for the treatment of myofascial pain syndrome from chronic muscle spasm. (2000) Pain 85: 101-105.

Pubmed | Crossref $\mid$ Others
Ommega Online Publishers

Journal Title: Journal of Anesthesia and Surgery (JAS)

Journal Short Name: J Anesth Surg
Journal ISSN: 2377-1364

E-mail: anestheisa@ommegaonline.com

Website: www.ommegaonline.org 